\title{
Reliability analysis of the Dual Mass Flywheel damping flange based on Workbench
}

\author{
Zhengfeng Yan ${ }^{1, a}$, Kunpeng Zhou ${ }^{1, b}$, Chunfang Liao ${ }^{2, \mathrm{c}}$ \\ ${ }^{1}$ School of Mechanical and Automotive Engineering, Hefei University of Technology, Hefei, 230009, \\ China \\ ${ }^{2}$ HubeiEngineeringInstitute, Huangshi City, Hubei Province, 435003, China \\ E-mail:amryzf99@yeah.net, bzhoukunpeng2011@163.com,'liaochunfang1973@sina.com
}

Keywords: stress analysis; fatigue analysis; flange; dual mass flywheel

\begin{abstract}
This article presents reliability analysis of damping flange from dual mass flywheel.In this paper, workbench software wasused to analyze the reliability of the dual mass flywheel damping flange. First, the mechanical model of the damping flange was built based on the dual mass flywheel's force transmission mode as well as the contact analysis model around rivet hole; then the finite element analysis method was used to solve the stress of damping flange based on previous mechanical model. Applied fatigue analysis in Design-life software for damping flange by the stress model from workbench software, the S-N curve was used to fatigue analysis, and gained the fatigue life distribution of the model. Finally, the durability test of the double mass flywheel carried in MTStest bench which deduced that damping flange meet the requirements of the application in the analysis and test.
\end{abstract}

\section{Introduction}

At present, the dual mass flywheel (DMFW) damper had become the best vibration isolation device in train system.The excellent isolation of torsional vibration and noise reducing, as well as sophisticated technology make DMFW more and more popular in the vehicle.

The study of DMFW last two decades from the beginning of the last century ninety's. In these years, the development of the DMFW had experienced several important milestone. The application of arc spring damper made dual mass flywheel almost solvesall problems about resonance. Then, the folded mass used in flywheel increased the moment of inertia of first flywheel in DWMF. As well as the cost of DMWF kept decreasing, whichmakes the DWMF widely used in train system.

In recent years, many scholars have studied the performance of vibration isolation of the DMFW, which consist of single-stage and multi-stage damping.Both the simulation analysis and test verification have been great developed $[1,2,3]$. However, the reliability of damping flange, the key part in the DWMF, is also very important. As a part in the dual mass flywheel, the main role of damping flange is transmitting torque from first flywheel to secondary flywheelas a power transmitter. The damping flangecan work normally in its whole life, which is very important for the DMWF. This paper introduces one method to forecast fatigue life of damping flange.Firstly, get the static stress of flange through workbench software, then,the fatigue life is acquired by design-life software with s-n curve.

\section{Mechanical model of damping flange}

Under the external force, the stress would occur in engineering components.Because of the irregular shape of components and feature of loads, the stress distribution of components is not uniform. Normally, we need to pay attention to someplace which would occur concentrated force and bethe most dangerous position.If the most dangerous position meet the requirements, the component would meet the requirements [4].

\section{1 mechanical analysis of damping flange}

When working, first flywheel in DMFW transfer power to the two convex lugs of damping 
flange through an arc spring.Then,the power is transferred to secondary flywheel through the rotary rivets installed in rivet hole of damping flange. Mainly, the load is concentrated on two convex lugs and around the rivet hole when DMFW working.

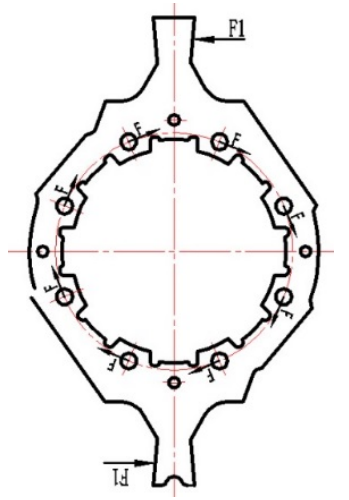

Fig. 1.1 Mechanical model.

Figure 1.1 illustrates the simplified force of damping flange. $F 1$ is theforce that the flange transmit, whosevalueis obtained according to the maximum torque $\mathrm{M}$ transferredby damping flange. F1 and M meet the following 1-1formula:

$F 1=M / 2 R(1-1)$

Where: $R$ is the working radius of damper'sspring;

$F$ is the force, acted by rivets,around rivet hole, and meet the following formula 1-2:

$F=M / n r(1-2)$

Where: $n$ is the number of rotating rivets, $r$ is the installation radius of rotatory rivets;

\section{2 rotary rivet contact model}

On the basis of the method of force transmission, there is elastic contact between rivets and rivet holes in flange. Figure 1.2 shows the contact mode of one of rivets and flange where R1 is the radius of rivets, $\mathrm{R} 2$ is the radius of rivet holes.

About contact theory, which was studied systematically by Hertz that had proposed the classical elastic theory, Hertz contact theory, early in 1882. And the theoryalso proved that the maximum compressive stress ontwo elliptical contact unit can be calculated according to the formula 1-3 [5,6].

$$
P_{0}=\sigma_{H}=\frac{3 P}{2 \pi a b}(1-3)
$$

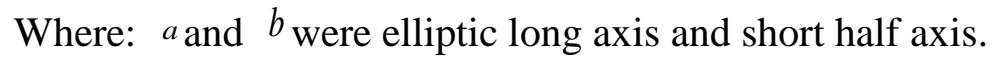

When the contact state is the cylinder with R1 radius into cylindrical hole with radius of R2 , and the material issteel with same elastic modulus $E_{1}=E_{2}=E$, the maximum contact stress on the contact surface could be introduced from the Hertz contact theory by formula (1-4) :

$$
P_{0}=\sigma_{H}=0.418 \sqrt{\frac{p E\left(R_{1}+R_{2}\right)}{R_{1} R_{2}}}(1-4)
$$




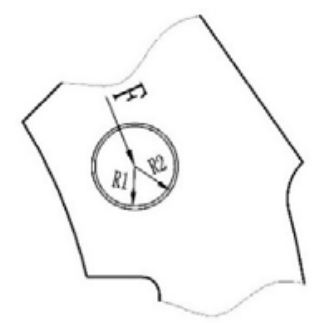

Fig.1.2 Rivet contact model

\section{Finite element analysis of vibration damper flange plate}

In recent years, finite element method is widely applied to get stress distribution in engineering components.Using the finite method to solve the stress of the model consistsof following steps, such as establishment of a three-dimensional model, meshing, adding boundary conditions for model, and solving [7].

\subsection{Build 3D model and meshing}

High accuracy of 3D model and mesh are critical in finite element analysis. In this paper three-dimensional model of the damping flange and rotary rivets wereestablished in software Pro-E.Then,assembled them together and exported them in IGES format. Imported the model into HyperMesh software and meshed.

The grid which type is quad was meshed in middle face with an appropriate size.Check grid quality after meshing and the quality of mesh showing as Fig2.1 shown.

\begin{tabular}{|c|c|c|c|c|c|c|c|c|}
\hline 1 & page 1 & 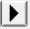 & \# fail & $\%$ fail & $\hat{\bar{\nu}}$ & worst & fail value & threshold \\
\hline$\sqrt{v}$ & min size & & 0 & 0.0 & woter & & 0.1 & $\begin{array}{lllll}0 & 7 & 7 & 0 & 0 \\
\end{array}$ \\
\hline$\sqrt{v}$ & $\max$ size & & 0 & 0.0 & wew & & 1.4 & 700 \\
\hline$\sqrt{v}$ & aspect ratio & & 0 & 0.0 & wet & & 5.0 & $\begin{array}{lll}0 & 0 & 0 \\
\end{array}$ \\
\hline$\sqrt{v}$ & warpage & & 0 & 0.0 & wew & & 15.0 & $\begin{array}{lll}0 & 0 & 0\end{array}$ \\
\hline$\sqrt{v}$ & skew & & 0 & 0.0 & weter & & 40.0 & $\begin{array}{lll}0 & 0 & 0 \\
\end{array}$ \\
\hline 浖 & jacobian & & 0 & 0.0 & were & & 0.6 & 000 \\
\hline
\end{tabular}

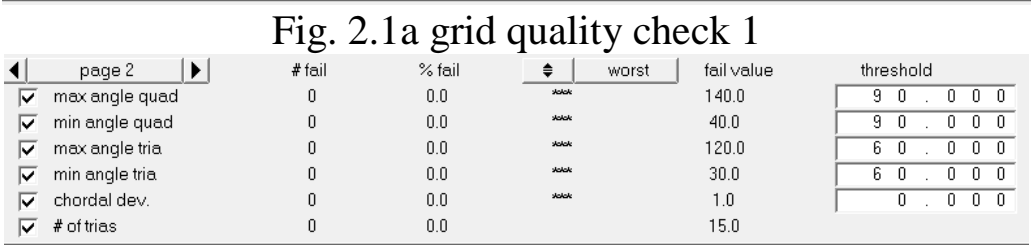

Fig.2.1b grid quality check 2

Fig.2.1 grid quality inspection

The hexahedral mesh was generated from quad grid which was qualified in check.And the hexahedral mesh was drag from quad grid with proper axial dimension.As shown in Figure 2.2, the mesh model of flange whichconsists of 91064 gridsand 106484 nodes.

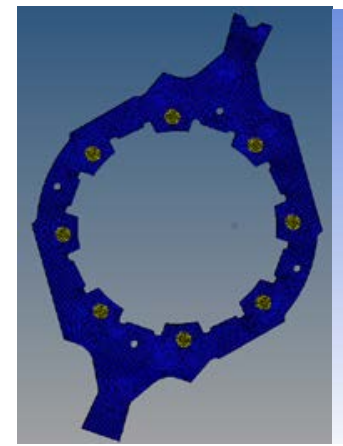

Fig. 2.2 mesh modelFig. 2.3 Contact pairs

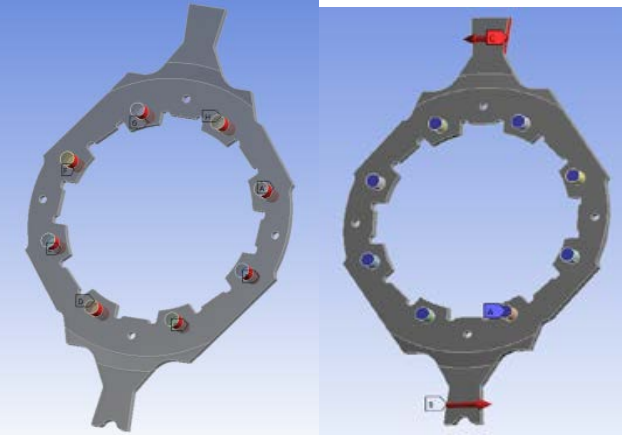

Fig. 2.4 Loads and constraints

The model was meshed in Hypermesh software and exported in cdb format which can import into workbench software for next step of FEM.

\subsection{Define material properties}

In order to ensure the finite element model with high accuracy and get more accurate stress distribution of the structure,the material properties of the model must be defined correctly. Usually, the material properties consist of elastic modulus、 poison ratio and density for static analysis. 
The material properties need to be defined into relative parts in the process of analysis. Defined material 45 steel into flange and material ML 10 into rivets in the material definition scene of workbench. Such as the material properties of 45 steel is: elastic modulus E=2.11e+11Pa; Poisson's ratio u $=0.269$; density $\rho=7890 \mathrm{Kg} / \mathrm{m} 3$.

\subsection{Add boundary conditions and contact pairs}

When established the contact pairs for respectively rivets and rivet holes in flange, selected the cylindrical surface of rivet target surface and the inner surface of cylindrical rivet hole contact faces in workbench. The contact pairs established shown as in figure 2.3. The contact pairs was set into smooth and turn the large deformation control on.

After establishing the contact pairs, the loads and constraints need to be applied. As shown in figure 2.4, the loads and constraints. Selected loads into concentrated load and the magnitude of loads could be obtained from formula 1-1. In this paper, the magnitude of loads is $3040 \mathrm{~N}$, the position was defined shown as in the red part of figure 2.4. The constraints were selected into fixed constraint and the position was set to two end surface shown as blue face in figure 2.4. When the boundary conditions was set, started solving.

\subsection{Static stress calculation results}

After solving, the stress distribution of flange shown as in figure 2.4, the static stress distribution.

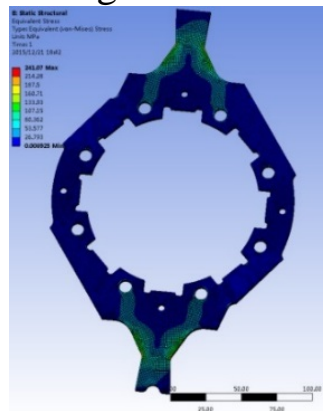

Fig.2.5 Static stress distribution

From finite element analysis results, we can find that the static stress distribution of flange when working is not uniform. There two convex lugs and around the rivet hole are obvious stress concentration problem. And as shown in figure2.5, the maximum stress, $246 \mathrm{Mpa}$, occurred in two convex lugs.

\section{Vibration damper flange fatigue analysis}

The fatigue life, one of the evaluation standard of reliability for engineering components, plays a crucial role in the reliability analysis. When engineering components loads cyclic loading, fatigue damage accumulation, the safety stress of engineering components would continue to fall until it fail.In this paper, the linear fatigue damage accumulation theory with S-N curve was used to fatigue analysis for flanges.And the simulation of fatigue analysis was carried out in software node-designlife, where got the fatigue life distribution of flange[8,9] .

\subsection{Linear accumulated fatigue damage theory}

Linear accumulated fatigue damage theory is that the fatigue damage is cumulative under cyclic loading, and when the cumulative damage reaches a certain value engineering components would failed to use. The Palmgren-Miner theory, also called Miner theory, is the typical theory of linear accumulated damage theory. And, Miner theory set that [10]:

(1) The damage caused by one cycle :

$$
D=1 / N \quad(3-1)
$$

Where: $N$ is the fatigue life corresponding the current loading;

(2) The damage caused by $n$ times constant amplitude loading cycles:

$$
D=n / N
$$


The damage by $n$ times variable amplitude loading cycles:

$$
D=\sum_{i=1}^{n} \frac{1}{N_{i}}
$$

Where: $N_{i}$ is the fatigue life corresponding to the current load;

(3) The critical fatigue damage $D_{C R}$ : If the cyclic loading keep constant amplitude, when the number of loading cycles $n$ is equal to the fatigue life $N$, there will be fatigue failure.

\subsection{Fatigue simulation}

In this paper, the simulation of flange fatigue analysis was applied in ncode-designlife software which can read static analysis results from various software.

The fatigue analysis also requires a corresponding material S-N curve which usually gained through the test, butthe ncode-designlife software could also simulate the material S-N curve for fatigue analysis by the input material's ultimate tensile strength [11,12,13].

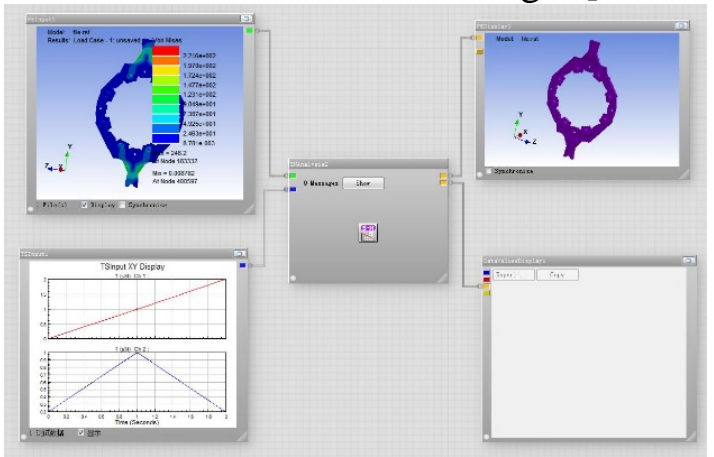

Figure 3.1 Fatigue analysis module

The fatigue analysis module in ncode-designlife was equipped as figure 3.1 shown. In loading settings, set the fatigue load stress ratio to 0.2. In the materialsetting, andset material's ultimate tensile strengthand the curve correction of S-N curve to Goodman method.The S-N curve that the software simulated shown as figure 3.2.
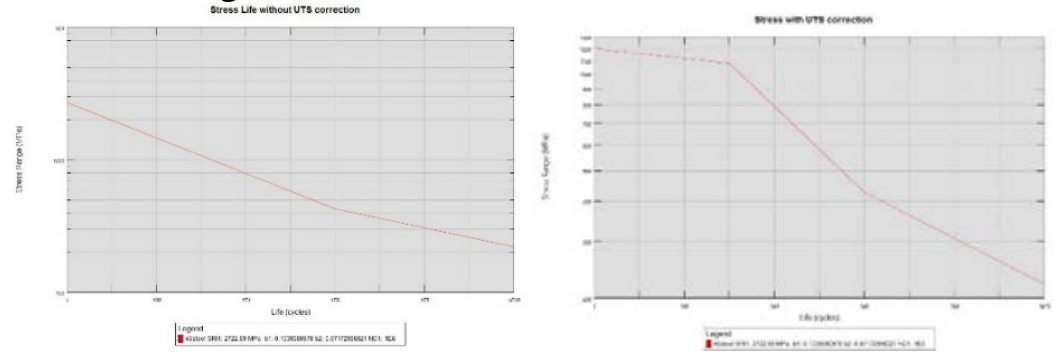

3.2a Stress life without correction3.2b Stress life with correction

Fig. 3.2 S-N curve of material

Run to solve above model would got the fatigue life distribution shown in figure 3.3 and the fatigue life of risk nodes shown in figure 3.4.

As it shown in figure 3.3, we can tell that the most dangerous point of the flange is the stress concentration position, but also the most severely damaged position. And the lowest node is the NO.147731 node. 


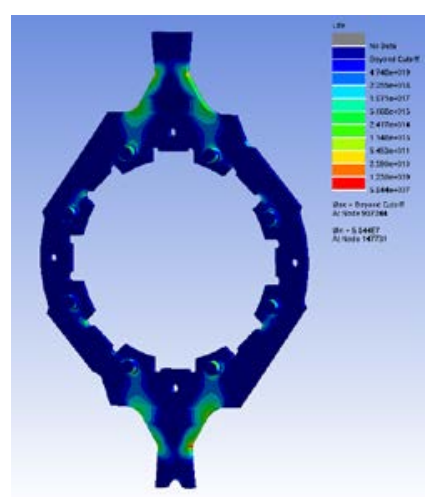

Fig. 3.3 Fatigue life distribution

\begin{tabular}{|c|c|c|c|c|c|c|c|c|c|c|}
\hline & 1 & 2 & 3 & 4 & 5 & 6 & 7 & 8 & 9 & 10 \\
\hline & Bode & Staell layer & Iaterial Grouz & Property ID & Aaterial ID & Denage & Iean biexialit & $\sqrt{30 a-p r o p o r t i c e}$ & Dowinant stress & Life \\
\hline & & & & & & & & & degrees & Repeats \\
\hline 107114 & 14771 & $\mathrm{z} / \mathrm{A}$ & All eulities & 1 & 1 & $1.711 \div 00$ & 0.06045 & 0 & 09.40 & 5.0448107 \\
\hline 167313 & 33202 & I/k & Al1 entities & 1 & 1 & 1. $104 \mathrm{e}-08$ & 0.09476 & $6.807 \mathrm{e}-09$ & -89.98 & $9.058 \mathrm{e}+07$ \\
\hline 167312 & 355698 & $3 / \mathrm{k}$ & Al1 entities & 1 & 1 & $1.099 e^{-08}$ & 0.09048 & 0 & 89.8 & $9.099 \mathrm{e}+07$ \\
\hline 167311 & 33221 & $\mathrm{z} / \mathrm{h}$ & M11 entitics & 1 & 1 & $1.0060=08$ & 0.000077 & 0 & -89.68 & 9. $212 \mathrm{e}+07$ \\
\hline 167310 & 3558989 & $\mathrm{z} / \mathrm{k}$ & All entities & 1 & 1 & $1.003 e^{-00}$ & 0.08289 & 0 & -69.58 & 9. $9660 \mathrm{e}+07$ \\
\hline 167309 & 149804 & $3 / k$ & All entities & 1 & 1 & 9. $353 z^{-09}$ & 0.0821 & 0 & 89.9 & $1.069 \mathrm{e}+108$ \\
\hline IfT:MR & 20799 & $3 / k$ & all entitios & 1 & 1 & B. 199s-19 & n m men & n & -9957 & 17 notir \\
\hline 167307 & 148847 & $\mathrm{z} / \mathrm{k}$ & All entities & 1 & 1 & $8.077 e^{-009}$ & 0.05333 & 0 & -80.30 & $1.238 \mathrm{t}+08$ \\
\hline $16 T 306$ & 148613 & $\mathrm{~g} / \mathrm{h}$ & ALl entities & 1 & 1 & 7. $5 b 6 e-1 y$ & U. Wosyl & iv & 89.81 & 1.267?t116 \\
\hline 167306 & 353008 & $3 / \mathrm{h}$ & All entities & 1 & 1 & 7. $949 \mathrm{e}-09$ & 0.06596 & $6.29 \mathrm{e}-09$ & 89.87 & $1.258 \mathrm{e}+108$ \\
\hline 167304 & 199005 & $3 / k$ & W11 entitios & 1 & 1 & $7.883 *-09$ & 0.07637 & 6. $2 v-10$ & -89.98 & $1.268 \mathrm{q}+108$ \\
\hline 167303 & 199196 & $\mathrm{z} / \mathrm{k}$ & All entities & 1 & 1 & 7. . T34e-09 & 0.06575 & 0 & 89.57 & $1.299 \mathrm{~s}+106$ \\
\hline 167302 & 32788 & $\mathrm{z} / \mathrm{k}$ & All entities & 1 & 1 & $7.647 e^{-09}$ & $0.08 c 29$ & 10 & 89.83 & $1.3008+108$ \\
\hline 167301 & 355697 & $\mathrm{I} / \mathrm{k}$ & All entities & 1 & 1 & 7. $452 e^{-09}$ & 0.07394 & 0 & 89.08 & 1. $342+108$ \\
\hline 167300 & 350000 & I/k & Al1 entities & 1 & 1 & 7. $427 t-00$ & 0.06721 & 0 & -80.82 & $1.346 \mathrm{e}+108$ \\
\hline IDTCSY & 321186 & $\mathrm{y} / \mathrm{h}$ & All entities & 1 & 1 & 7.34tove-vy & U. UESCI & 3. $.465-\mathrm{V} U \mathrm{Y}$ & 84.64 & 1. 360 let165 \\
\hline 167228 & 33225 & $8 / k$ & Al1 entities & 1 & 1 & $7.2748-09$ & 0.08238 & 0 & 89.73 & $1.375 \mathrm{e}+108$ \\
\hline 167297 & 150676 & $3 / k$ & All entitios & 1 & 1 & 6. $8544-09$ & 0.07934 & 8. $581 \%-10$ & 99.88 & $1.4598+08$ \\
\hline 167296 & 150887 & $3 / \mathrm{h}$ & A11 entities & 1 & 1 & 6.632e-09 & 0.08134 & 0 & 69.44 & $1.500 \mathrm{e}+06$ \\
\hline 167285 & 150659 & $3 / k$ & All entities & 1 & 1 & 6. $334 \mathrm{e}-09$ & 0.06413 & $6.71 e^{-10}$ & 89.3 & $1.579 \mathrm{e}+108$ \\
\hline 167294 & 150677 & $\mathbf{Z} / \mathrm{k}$ & Al entities & 1 & 1 & 6. $1728=-09$ & 0.07751 & 4. $112 e-09$ & -89.87 & 1. $62 \mathrm{e}+108$ \\
\hline 167283 & 1147728 & $3 / h$ & MII entitios & 1 & 1 & $6.08 \mathrm{c}-09$ & 0.03135 & 0 & 89.51 & $1.645 \mathrm{c}+108$ \\
\hline 167298 & 353014 & $y / k$ & all entities & 1 & 1 & 5. $944 e^{-09}$ & 0.07762 & 10 & 89.62 & $1.6822+06$ \\
\hline 167291 & 168844 & $\mathbf{3} / \mathrm{k}$ & All entities & 1 & 1 & $5.863 e^{-09}$ & 0.030075 & 10 & 89.72 & $1.72+08$ \\
\hline 167790 & 15NFF & $\mathrm{z} / \mathrm{h}$ & 211 entitios & 1 & 1 & 5 4 $433-19$ & n ก m1\% & n & $-\$ 99$ & 18 SAloth \\
\hline 107209 & 148214 & $\mathrm{I} / \mathrm{k}$ & Al1 eulitites & 1 & 1 & $5.07=09$ & 0.07790 & 0 & 09.94 & $1.972 \varepsilon_{100}$ \\
\hline 167288 & 199222 & I/k & Al1 entities & 1 & 1 & $4.97 e^{-09}$ & 0.05872 & 4. $.979 e-09$ & -89.7 & $2.012 \mathrm{e}+108$ \\
\hline 167287 & 150684 & $\mathrm{I} / \mathrm{k}$ & All entities & 1 & 1 & $4.673 e^{-09}$ & 0.06686 & 0 & 89.96 & 2.14e+108 \\
\hline 167208 & 33223 & $8 / \mathrm{h}$ & MI1 entities & 1 & 1 & 3.88Re -08 & 0.04678 & 0 & 89.14 & $2.568 \mathrm{c}+108$ \\
\hline 167285 & 1482223 & $\mathbf{y} / \mathrm{k}$ & Ml1 entities & 1 & 1 & 3. $869 e-09$ & 0.05582 & 10 & -89.76 & $2.571 \mathrm{let}+03$ \\
\hline 167284 & 146734 & $3 / k$ & Al1 entities & 1 & 1 & 3. $7366=-09$ & 0.02406 & $1.385 \mathrm{e}-08$ & 27.63 & $2.677 \mathrm{e}+108$ \\
\hline $167 \% 3$ & \begin{tabular}{|l|l|} 
ank33 \\
\end{tabular} & $\mathrm{z} / \mathrm{k}$ & In1 entitios & 1 & 1 & $3.5 \% 5=-19$ & n 10194 & 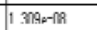 & m n & P AGsoth \\
\hline 107202 & 197014 & $3 / \hbar$ & Al1 eulities & 1 & 1 & $3.50=09$ & 0.00072 & 3.101ะ 09 & 27.09 & 2.0098100 \\
\hline 167861 & 150683 & $y / h$ & All entities & 1 & 1 & $3.214 e^{-11}$ & U.ublsb & iv & 84.7 & 3.111e+168 \\
\hline 167280 & 3906 & $3 / k$ & Al1 entities & 1 & 1 & 3. $141 \mathrm{e}=-09$ & 0.03138 & $7.597 \mathrm{e}-09$ & 20.53 & 3.184et+108 \\
\hline 167279 & 165200 & $3 / k$ & L11 entitios & 1 & 1 & 3. $13 \mathrm{v}-09$ & 0.04152 & 0 & -89.87 & $3.195 \%+08$ \\
\hline 167278 & 148043 & $3 / \hbar$ & M11 entities & 1 & 1 & 3.004e 09 & 0.02676 & 0 & 89.62 & $3.329 \mathrm{e}+06$ \\
\hline 16727 & 32987 & $3 / \mathrm{h}$ & All entities & 1 & 1 & $2.813 e^{-09}$ & 0.05099 & 0 & 89.62 & $3.555 \mathrm{t}+108$ \\
\hline 167276 & 150630 & $\mathrm{I} / \mathrm{k}$ & Al entities & 1 & 1 & 2. $485 \mathrm{e}-09$ & 0.07965 & $4.331 \mathrm{e}=09$ & -69.39 & $4.009 \mathrm{e}+103$ \\
\hline 167275 & 150622 & $\mathbf{Z} / \mathrm{k}$ & All entities & 1 & 1 & 2. $443 e-00$ & 0.07488 & 0 & -80.06 & $4.004 \mathrm{se}^{+108}$ \\
\hline IETCZ14 & $15062 y$ & $8 / \hbar$ & ALI entities & 1 & 1 & 2. 2.8Se-1y & 0.000016 & iv & -68.62 & 4. $36 \mathrm{set}$.16 \\
\hline 167273 & 146206 & $\mathbf{y} / \mathrm{k}$ & Al1 entities & 1 & 1 & 2. $158 \mathrm{e}-09$ & 0.00016 & 0 & 89.94 & $4.633 t+108$ \\
\hline 167272 & 149158 & $3 / k$ & |ll entitios & 1 & 1 & $2.068 \mathrm{v}-09$ & 0.0888 & 10 & -88.84 & $4.837 \%+08$ \\
\hline 167271 & 149177 & $\mathbf{z} / \mathbf{k}$ & Al1 entities & 1 & 1 & $2.086 e^{-09}$ & 0.08400 & 10 & 69.5 & 4.84 t00 \\
\hline 167270 & 199169 & $\mathbf{3} / \mathrm{k}$ & All entities & 1 & 1 & $2.064 e^{-0}-0$ & 0.07883 & 0 & -69.52 & $4.846 \mathrm{e}+108$ \\
\hline
\end{tabular}

Fig. 3.4 Fatigue life of risk nodes

\section{Fatigue endurance test}

The Fatigue Endurance Test was carried out on the MTS torsion test bed. As shown in Figure 4.1, the MTS test bed mainly consists of loading system, data acquisition system and control system. Besides, the MTS test bedcould simulate full range torque and speed of engine torsional vibration.

The double mass flywheel was installed on the loading axis of the test bed. Meanwhile, the loading shaft was locked to adjust the speed and torque of the test table. The flange of double mass flywheel was taken out after ten million times cyclic loading.

As shown in Figure 4.2, the tested flange doesnot occur fatigue failure, show cracks on the surface and observable deformation, which indicates the flange is meet the using request. 


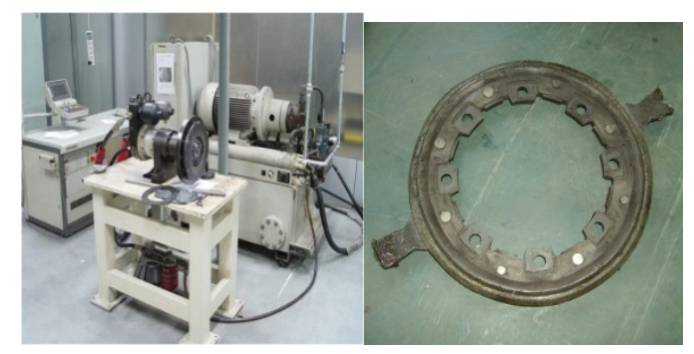

Fig.4.1 MTS test bed

Fig. 4.2 Tested flange

\section{Concluding remarks}

In the process of stress analysis of flange, this paper established the model with contact of flange and rivets.And the software workbench and ncode-designlife was used to simulate the static stress and fatigue of flange. The following conclusions are concluded through the results of static stress and fatigue analysis.

(1) The flange can bear the maximum stress within the material yield limit in the case of transferring the maximum torque. But there are stress concentration problemin two convex lugs and around the rivet hole. This paper also provide the static stress and fatigue distribution of flange, in accordance with which the flange would be further optimal design.

(2) Based on the analysis results by the Design-lifesoftware, the flange can bear cyclic loading more than ten million times, which meets the use requirements. And the most severe fatigue damage, two convex lugs of flange,is the stress concentration position.

\section{References}

[1] Yin Yuming: Modeling and simulation of dual mass flywheel's torque characteristics[J]. Journal of Chongqing University, 2013.5 Vol.36 No5: 18-24.

[2] Chen Lei.Reseach on dynamic characteristics of passenger car dual mass flywheel[D]. Journal of Wuhan University of Technology.2009

[3] Liu Yun. Study of torsional vibration characteristic of dual mass flywheel system [D].Journal of Wuhan University of Technology.2009

[4]Wang Wangyu.Automotive design [M]. China Machine Press. 2004.8 version fourth

[5]Johnson K.L. Contact Mechanics[M]. Press Syndicate of the University of Cambridge.1985:15-65.

[6] Yan Huangdong. Contact stress analysis of pinned connection[J].Engineering Mechanics.2008.1 Vol.25 No1 (229-240)

[7] Leng Jitong. Finite element technique foundation [M]. Chemical Industry Press.2007:3-15.

[8]Zhao Shaobian. Anti-fatigue design [M]. China Machine Press 1994:10-50.

[9]Li Yuchun. Nonlinear micro mechanical model of high cycle fatigue crack initiation [J]. Journal of Nanjing University of Aeronautics\& Astronautics. 1998.6. Vo.30 NO3 261-266

[10] Yao Weixing. Fatigue Life Prediction of Structures[M]. National Defend Industry Press2003,P(76-80).

[11] Wang Yanwei. FEA based fatigue analysis and its application[J]. Machinery design \& Manufacture. 20081 No1 (22-24)

[12] Zhang Xiang. A method of calculating the whole life element with hole crack formation and crack propagation [J]. Journal of northwestern polytechnical university.1984.10 Vol2 No4. (381-392)

[13] Zhang Linbo. Full life calculation method of crack formation and crack growth with hole element. [J] COMPUTER AIDED ENGINEERING.2006.9 Vol.15 (198-202). 